This is the accepted version of the manuscript published by Wiley in Child \& Family Social Work, doi: 10.1111/cfs.12077

Sheppard, M., \& Clibbens, J. (2015). Preventive therapy and resilience promotion: an evaluation of social work led skills development group work. Child \& Family Social Work, 20, 288-299.

\title{
Preventive therapy and resilience promotion: an evaluation of social work led skills development group work
}

\section{Summary}

Concerns have been expressed for some time about a decline in emphasis on therapeutic work in social work, notably articulated in the Munro Review. Further concerns have been expressed, in child care that social workers have increasingly had to focus on child protection work rather than earlier stages of prevention. However, there remain opportunities for social workers through the development of new programmes. One development has been that of Behaviour and Education Support Teams: multi professional teams, containing as a key element social workers, and encouraging novel practices designed to help emotional stability and improved behaviour and education performance. This study reports on an evaluation of a social worker delivered school based social skills programme which can contribute to the important area of resilience. This showed significant and sustained improvements in prosocial behaviour and friendships. The implications of this for the therapeutic potential and professional role of social work are discussed. 


\section{Preventive therapy and resilience promotion: an evaluation of social work led skills development group work}

\section{Introduction}

Developments in child care practice in recent decades - driven in part by a reaction to highly publicised child deaths and a growing emphasis on managerialism in general and care management in particular (Postle, 2002) - have led to a form of social work practiced, many believe, in an over-mechanistic way. Howe (1996) suggested we are increasingly concerned with surface features, rather than the underlying mechanisms that produce the difficulties faced by individuals, families and groups. An obsession with IT and recording, often at the expense of face-to-face work with families has, suggest Broadhurst et al (2010) actually increased the possibility of systemic risk and hence dangers to children. The influential Munro Review of Child Protection (2011, p 6), commented that 'insufficient attention is given to developing and supporting the expertise to work effectively with children, young people and families'. One neglected feature of this expertise is, according to Munro (2011, p 88-9), the therapeutic bond established between social worker and client.

Many of these concerns are expressed in relation to the traditional settings for social work practice - in particular the local authority settings of children and adult services (Axford and Little, 2006). However, in other settings social workers have had opportunities to carry out the more therapeutic interventions traditionally characteristic of the profession. Interventions designed to ameliorate and resolve familial and child problems are apparent in child care, for example, in the work of social workers in the NSPCC, Action for Children and Barnados

\section{Behaviour and Education Support Teams}

An alertness to the opportunities for demonstrating the capacity to carry out these therapeutic capabilities is incumbent upon those who see this as a central element of social work. One potential area for innovative practice has been provided by Behaviour and Education Support Teams (BESTs) now sometimes called Targeted Youth Support Schemes ${ }^{1[1]}$ (TTRB, 2010).

BESTs comprised multi-agency teams with work aimed at the identification of children and their families who are at present, or, who are at risk of, developing emotional, behavioural and attendance problems, to help in the prevention of such development, and to carry-out early intervention work (DfCFS, 2008; Halsey, et al., 2005). Their focus has been on school-aged children and they have been associated with a cluster

${ }^{[1]}<![$ endif] $>$ Many teams retain the BEST title, e.g. Cleveland, Liverpool and Salford (all 2012) 
of schools within defined locations. Typically comprising at least five practitioners from health and social care professions, social work has been a key element. The goals have been to 'promote emotional well-being, positive mental health, positive behaviour and school attendance. through the provision of multi-agency support in target schools and to individual families' (Cowan, 2004). A recent study has shown them to operate in a more preventive way than area child care social work services, to focus on families in need and to be child centred (Sheppard and Clibbens, 2012)

BESTs have taken quite diverse forms in an effort to be responsive to local need. Some, for example are located on school premises, while others are not; some limit referrals to school professionals (or even heads) while others have a wider referral base, including parents carers and the children themselves (DfCFS, 2003). Social workers, though, have a high profile in BESTs which frequently employ more than one from that profession.

BESTs have been encouraged to be innovative. Thus a range of approaches may be adopted including, for example, group support to children and parents, including nurture groups, transitional groups and parenting groups, intensive case managed support for children and families, and support for schools, through, for example, consultancy to individual staff or developing whole school strategies (DfCFS, 2008).

There are some limited evaluation findings on pilot BESTs, and these focus on their ability to meet their general objectives. The main foci for these studies have been on issues such as the impact of BESTs on schools, on external agencies, multi agency work including communication, their appropriate location, and the impact of interventions. In general findings are positive in all areas (for example facilitating multi agency work, sensitising school staff to the relationship between school performance and familial context, creating interventions valued by parents) except where different alternatives are being considered (the value of a school versus community location may vary according to locality) (Halsey et al, 2005; Stallard-Nash, 2005; Ainscow and Francis, 2005). Evaluations are general, and remain at an early stage. The predominant methodology is qualitative and findings are generally based on stakeholder opinions, rather than, say, detailed baseline-follow up outcome evaluations.

\section{Social work and social skills - Social skills and resilience}

BESTs nevertheless provide an excellent environment for the development and evaluation of innovative practice focusing on vulnerable families below those that would be classified as 'high risk' (Sheppard and Clibbens, 2012). Amongst the key opportunities is the promotion of resilience and positive mental health. Resilience refers to the capacity of an individual to cope with and overcome environmental adversity and is of considerable importance to children and young people who might be exposed to such risk through loss, deprivation disadvantage or poor familial 
environment (Rutter, 2006). Resilience places an emphasis less on the child as 'victim' than their capacity to negotiate and overcome adversity.

The capacity to develop resilience is therefore of considerable significance for those involved in helping children overcome adversity or who seek to help children develop this capacity. In this respect the development of social skills is of some importance. There is evidence of a clear association between social skills and resilience, particularly amongst vulnerable children and young people (Conway and McDonough, 2006; Thompson, 2006). The connection is not surprising since they are apparent in building and maintaining social relationships, they contribute to the development of personal identity and enable coping with stress and transition.

Poor social skills, on the other hand, are associated with emotional and behavioural problems and school failure (Buhs \& Ladd, 2001; Gifford-Smith and Brownell, 2002). Emotional and behavioural problems identified in class have, in turn, been associated with antisocial behaviour (Patterson et al, 1992; McCrystal et al, 2007), crime (Loeber \& Dishion, 1987), drug use (Fergusson et al, 1995, Liddle, 2004), sexual precocity (Capaldi et al, 1996; Bennet, 2006) and school disaffection and failure (Walker et al, 1995; Needham et al, 2004). Schools, then, provide an obvious point of access for children who may benefit from skills development.

Social skills development therefore has an important preventive function arising from its capacity to enhance resilience in children and young people and specifically the appropriateness of the classroom as a setting for such activity (Wilson and Lipsey, 2007). Daniel (2002) and Gilligan (2004) argue the promotion of resilience is a key social work task. A more school focused form of social work offers the opportunity for practitioners to engage in these activities. However, the capacity to carry out such interventions cannot be assumed, since they frequently involve specialist interventions which can extend beyond the normal curriculum of social work education and training. How effectively can social workers carry out classroom based social skills development in children? And (as is often the case) if there is no formal training available, are they capable of the self-taught development of intervention skills? This study reports on a longitudinal, repeated measures, control trial of the impact of a class based, social worker led, social skills development in cohorts in two schools.

\section{Area and Methods}

\section{The Approach}

The schools were part of a cluster in a former Health and Education Action Zone in a predominantly rural county. The classes were from years 5 and aged between 9 and 11. The school cluster associated with the BEST was in a district with a population of just over 92,000 , half of which were in three towns in the area: a mixture of a small 
town and rural population. The district was amongst the 25\% most deprived in England and Wales (Index of Multiple Deprivation) with associated low incomes and high levels of unemployment relative to the rest of England and Wales. Attainment levels at key stage two were a little lower than that for England and Wales as a whole, but school exclusions were similar. The proportion of families with lone parents, at just over $7 \%$, was similar to England and Wales as a whole

The junior schools within the cluster were made aware of the offer by BEST social workers to provide brief, structured class based skills training where they had (1) experienced conduct or peer problems that they regarded to be above that which they would normally have expected (2) that this presented difficulties in class management likely to affect the education the children would receive. The philosophy behind this approach was explained and two schools took up this offer for children in years five and six, in which children were aged between 9 and 11 .

Of particular importance to this philosophy were four features. First there was an emphasis on the importance of brief, structured intervention designed to enhance class member's (pupils') social skills. Second the classroom provided the group context. This would provide a 'natural environment' to which the pupils would be used, providing a more immediately comfortable context than would have been the case had the group taken place in a room to which they were not accustomed. Third (also emphasising the 'natural environment') it would occur in the class context, in which the difficulties identified by the schools had manifested themselves in the first place, and which would continue to provide the routine venue for their subsequent education. Finally, there was a 'whole class' approach. Rather than identify the 'difficult children' the work would be undertaken with the whole class. This both prevented the special selection (and hence possible stigmatising) of 'difficult children' and also emphasised the interactional context for problems emerging. Rather therefore than viewing the problems as being inherent solely in the children (and hence creating a group of 'difficult children'), the class itself was viewed as the environment in which (at least in part) these emerged.

Each Group was five weeks in length, and adopted a slightly amended schedule from the work of Spence (1996a \& b). The social workers employed a self-learning approach - they taught themselves - through the use of Spence's materials. Spence's approach focuses on three key elements: cognitions, behaviour and feelings, all of which seek to enhance interpersonal functioning and social competence. Underlying these are certain principles: the importance of the active involvement of participants (in this case the children); that of observation as a key part of the learning process; and of practising as a way of developing their skills.

The approach, in practical terms, includes a range of elements: instruction, discussion, demonstration (modelling) role play and feedback. These elements enabled both training (through instruction) and engagement (through discussion role play and 
feedback) of those involved. Spence (1996a) indicated that this could be used with children in groups up to a full class size.

The sessions involved the following work, corresponding to work in sessions 1, 2, 3, 5 and 6 in Spence (1996a):

Week 1: Introduction, setting up group rules, 'getting to know me activities'

Week 2: Feelings and their effects on behaviour. This involved the use of cue cards (with 'feeling names' on them), a focus on posture and body language and the exploration of feelings, including through mime

Week 3: Involved further exploration and learning about feeling, including awareness of how feelings 'feel' and their effects on behaviour (and vice versa)

Week 4: focused on communication skills, particularly eye contact, observation and listening skills and friendship skills. Friendly and unfriendly behaviours were explored, and role play was part of the work

Week 5: Conflict and unhelpful thoughts; the 'social detective' (detecting and responding to unhelpful social interactions); closure.

The overall aim was: to improve the social skills of the children in the class, as a whole

The following Hypotheses were adopted: that compared with the C Group

1. the E group would show significantly greater reductions in peer problems, and associated problem areas of emotional symptoms, conduct and hyperactivity

2. the E group would show significantly greater improvements in Prosocial Behaviour

3. the E group would show a significantly greater increase in friendships

4. the E group would show significantly reduced destructive expression of anger and significantly increased positive coping behaviours

A further hypothesis was that

5. improvements achieved by the $\mathrm{E}$ group would be sustained 3 months following the completion of the skills group

\section{The Evaluation}

A Repeated Measures Control Trial was adopted, in which the children in the two classes acted as their own controls. This was achieved by carrying out measurements over similar time periods but at different times (one following on from the other). The skills class was conducted over five weeks and the control trial was designed to accommodate this. 
In relation to the Control Trial, data were collected at three points, enabling measurement of change in both experimental and control groups over identical time periods. These were (a) during the seventh week before the group [T1] (b) during the week before commencement of the group (six weeks later) [T2] (c) during the week after the group finished (six weeks after (b)) [T3]. Measures (a) and (b) were used to calculate changes in the control group, (a) being baseline and (b) being follow up for the control group. Measures (b) and (c) were used to calculate changes in the experimental group, (b) being baseline and (c) being follow up.

However, in addition we wished to discover the extent to which improvements (if they occurred) could be sustained. In relation to the second class, therefore, we carried out measurements at a further, fourth, point, 3 months after completion of the skills class (measure (d) or T4). The process can be summarised as follows. 


\begin{tabular}{|c|c|c|c|c|}
\hline & \multicolumn{2}{|c|}{ Class A } & \multicolumn{2}{|c|}{ Class B } \\
\hline & E & C & $\mathrm{E}$ & C \\
\hline T1 & & $X$ & & $X$ \\
\hline $\begin{array}{l}\text { T2 Start of } \\
\text { Group }\end{array}$ & $x$ & $X$ & $x$ & $X$ \\
\hline $\begin{array}{l}\text { T3End of } \\
\text { group }\end{array}$ & $x$ & & $x$ & \\
\hline $\begin{array}{l}\text { T4 End of } \\
\text { group }+3 \\
\text { months }\end{array}$ & & & $x$ & \\
\hline
\end{tabular}

The children included were only those who were present for all three measures (in Class A) and all 4 measures (class B). Illness, other reasons for non-attendance at any one of the measurement points and change of schools by some pupils all restricted the number. Hence, from the two classes, respectively having 30 and 28 children, each provided 21 participants. Both the $\mathrm{E}$ and $\mathrm{C}$ groups, therefore, comprised 42 children.

A number of instruments were employed. We used the teacher version of the Strengths and Difficulties Questionnaire (SDQ), a widely utilised reliable and valid instrument (Goodman, 1997, 2001; Goodman et al 1998). This was used because: our focus was on problems and issues identified in the classroom; the group occurred in the classroom and the teacher's sustained contact with the children meant they were in a good position to complete the SDQ in a highly informed manner. The SDQ distinguishes between 'normal', abnormal' and 'borderline' states. It has five subscales focusing on psychological attributes: emotional symptoms, conduct problems, hyperactivity/inattention, peer relationship problems and prosocial behaviour, as well as an overall score derived from all the subscales except prosocial behaviour.

The other instruments were completed by the researcher with the children. The MultiDimensional School Anger Inventory (MDSAI) (Furlong et al, 2002) is an instrument of known reliability and validity, which is used to assess anger within a school setting. The measurement of Anger has 17 items each relating to two underlying dimensions of the subscale: Destructive Expression and Positive Coping. Each item comprised a statement (e.g. 'when I am angry l'll take it out on whoever is around' or 'I'll talk it over 
with another person when I'm upset') scored on a scale from 1-4 (never, occasionally, often, always)

The Social Competence Questionnaire (Spence, 1996b) examines the management of friendships in social interaction. The instrument has ten items, each of which focuses on aspects of friendships. It includes, for example, statements such as 'My friendships with other kids last a long time', 'I find it easy to make friends' and 'I see my friend or friends at weekends'. The children rate each of these items as one of the following 'not true' (score=0), 'sometimes true' (score=1) and 'mostly true' (score=2).

Assessing number of friends: we additionally sought to obtain a quantitative measure of the number of peers each child regarded as friends. Rather than ask a direct question on the number of friends they thought they had (which we considered would lead to inaccuracy) we sought to itemise them by name, one by one. Hence we asked them to give us the name of each person who (a) they played with a lot and/or (b) they regularly saw outside school. We computed the number of friends from the list compiled.

The groups were run by two female social workers. One was the team manager with over five years' experience in child protection, qualified with the Child Care Award. The other had one year's post qualifying experience. Both had honours degrees (2:1).

The research was carried out following approval by the University Research Ethics Committee. The school was of course acting in loco parentis. However, as part of the process, the research element was explained to the children on an individual basis including opt in and withdrawal rights.

\section{Results}

\section{The skills classes}

On referral, the classes were described by their respective teachers as (a) having above average problems with arguments between children, attentiveness within class, cooperativeness in class and bullying; and (b) having high levels of conduct problems and difficulties with attentiveness and concentration

Table 1 shows the levels of emotional behavioural and relationship problems in the classes, confirming the general impression of the teachers. Although the overall SDQ score was only a little higher than might be expected (10\% having clinical or 'abnormal' problem levels) school B had markedly raised hyperactivity and conduct problems, and school A had especially high levels of peer problems.

\section{$\underline{\text { Table } 1 \text { about here }}$}


Table 2 presents findings on emotional, behavioural and relationship changes. There were no significant differences between the experimental and control groups in hyperactivity, emotional, behavioural and peer problems. Indeed, where differences existed in these areas they were marginal, and could go either way (e.g. the control group showed marginally greater reduction in emotional symptoms and the experimental group marginally greater reduction in conduct problems). There was, however, significantly greater improvement in prosocial behaviour in the Experimental Group. Hypothesis 1, therefore, was falsified, but Hypothesis 2 was supported by the data.

\section{$\underline{\text { Table } 2 \text { about here }}$}

Tables 3 and 4 focus on the expression of anger and social competence/friendships. There was no difference between the experimental and control groups in positive coping (with feelings of anger) or in the ways in which the children saw themselves as managing friendships (social competence). However, there was significantly greater increase in the number of friendships identified by the children in the experimental group and significantly greater reduction in destructive expression of anger. Hypothesis 3 was therefore supported, although, perhaps surprisingly, without a concomitantly greater improvement in the $\mathrm{E}$ group in the management of friendships. Hypothesis 4 was partially supported (in the reduction in destructive expression of anger) but not supported in greater improvements in the experimental group in positive coping with feelings of anger.

\section{$\underline{\text { Table } 3 \text { about here }}$}

\section{Table 4 about here}

\section{Sustaining improvement}

We sought to discover whether improvements could be sustained, and took further measures 3 months after completion of the skills group.

Table 5 provides data from 3 months after completion of the skills group. It shows the improvements in prosocial behaviour, in relation to which the skills group had a significant impact, were maintained at 3 months. Other emotional, behavioural and social outcomes, however, having not been significantly affected by the skills group in the first place, showed significant improvements three months later. There were significant reductions in emotional symptoms, hyperactivity and overall SDQ scores,

\section{$\underline{\text { Table } 5 \text { about here }}$}


Reductions in the destructive expression of anger were not, however maintained. Table 6 shows that destructive expression became significantly more pronounced 3 months after completion of the skills group. On the other hand, positive coping and social competence, which were unaffected by the skills group, showed significant improvements at 3 months.

\section{Table 6 about here}

Table 7 shows that the number of friends, which had significantly increased in the skills group, was maintained, and, indeed there was some, though not significant, further increase.

\section{$\underline{\text { Table } 7 \text { about here }}$}

Hypothesis 5 was, therefore, partially supported, with improvements in number of friends and prosocial behaviour maintained, but reductions in destructive expression of anger not maintained. However, other aspects of the children's emotional behavioural condition and social relationships showed improvements subsequent to the completion of the group.

How big was the effect? Technically this is the percentage of dependent variable variance accounted for by membership of the independent variable. Effects are medium, $(\mathrm{d}=0.5)$ and large $(\mathrm{d}=0.8)$ as defined by Cohen (1988). Table 8 shows medium and large effects where significant differences were found. Of particular interest in relation to the immediate impact of the experiment, were prosocial behaviour and number of friends where, respectively, $12 \%$ and $9 \%$ of variance may be explained by the group, while $12 \%$ of emotional symptoms variance occurred through the three months follow-up

\section{$\underline{\text { Table } 8 \text { about here }}$}

\section{Discussion}

These findings, of course, report on innovative practice for social work, both in context and approach, and we must take account of this. Its novelty means that we have little to compare it with (there are no other similar studies of classroom based skills oriented social work practice, particularly employing a longitudinal control design). There is a number of further limitations. There were only two classes and the $E$ and $C$ groups each contained only 42 children. The social workers will have brought their own distinctive qualities to the process, and these can impact on outcome prospects (Lambert and Barley, 2002). Both these factors suggest we should be careful about generalising from these findings. The approach - a repeated measures control trial using children as their own controls - has considerable strengths (outlined above). We should note however that our findings reflect the time period covered. In particular the 
post intervention follow up was with one class at 3 months - we cannot tell, for example, whether improvements had been sustained, say, one or two years later (of course our methodology enabled us to establish whether improvements had been maintained three months after the completion of the group, an encouraging set of findings for the sustainability of social skills accretion). Likewise, maturation, as with other longitudinal designs, may have played a part. It focuses, furthermore, on children near the end of primary school. While this age has strategic potential for developing resilience (coming at the end of primary school years and immediately prior to secondary school) we cannot say whether results would be the same for other age groups (although this might be an interesting avenue for further study).

Overall, then, while outlining intriguing possibilities, in order to establish firmly social work's potential in this area we require further replication studies, particularly with longer post intervention follow ups, whose findings broadly confirm these. They have yet to be conducted.

Having stated these important caveats, which should be considered in relation to the following discussion, the findings can be considered in two ways: as a specific arena for practice, and in terms of its implications for the wider social work role.

The key findings of the control trial were (a) that the skills group was not associated, on any measure with deterioration, compared with the control group and (b) that in prosocial behaviour, number of friends and (reduction in) destructive expression of anger the skills group was associated with significant improvements. These are very important skills (and results) if children are to develop the kinds of social relationships which can be supportive and encourage resilience. As a caveat, identifying increased friendships as a positive may depend upon who they were: friendships reinforcing challenging, disruptive behaviour may not be positive. However, taken in context - improvements in prosocial behaviour and reductions in destructive expressions of anger - it seems likely that the increased friendships reflect improved social skills.

These findings generally show improvements in areas of social life involving relationships, rather than the more 'internal' (or individual) measures such as emotional symptoms and hyperactivity. Indeed, the improvement in 'relationship abilities' without a concomitant improvement in areas such as emotional symptoms and hyperactivity (which might be considered as potential inhibitors of improved relationships) is noteworthy. Yet (to anticipate later comments) improvements in prosocial behaviour and friendships (if not the destructive expression of anger) were maintained three months after completion of the skills group.

This may well reflect the nature of the learning by the children that occurred in the process of experiencing the skills group. This group, as we have seen, focused on the behaviours of the children in interaction with each other. It aimed to develop 
abilities to understand and 'read' each other, and to act in ways that would be viewed positively and foster constructive relationships. This, in effect, is the encouragement of prosocial behaviour, which refers to voluntary actions that are intended to help or benefit other individuals or groups. They are, in many respects, the behavioural manifestation of empathy, including, for example, sharing, comforting, and helping (Eisenburg and Mussen, 1989). The greater social awareness associated with these behaviours would be likely to be associated with less destructive expression of anger and an increase in the number of friendships, as was observed.

The absence of a corresponding impact on those measures of 'internal psychological' states, does, though, suggest some potential limits to the impact of these skills groups. If there was little impact on these states, particularly emotional symptoms and the impetus to hyperactivity, then there may be reason to believe that the effects of the skills group were superficial and transient - they were only affecting external behaviour and may well not be maintained.

However, the evidence does not suggest this, although it is not entirely unambiguous. The three month follow up, after completion of the skills groups, raises the problem of maturation - the children may simply have improved further because they became 'older and wiser' in their conduct of relations. However, of at least equal importance is that the positive changes which, on the evidence of the control trial, were engendered by the skills groups, were indeed maintained (in relation to prosocial behaviour and friendships if not destructive expression of anger). Reservations which might have existed about the sustainability of positive changes when examining only the $\mathrm{E}$ versus $\mathrm{C}$ group measures are not (on the whole) borne out by the 3 month follow up.

Indeed, we might go further - while maturation may have played a part, the scale of the further improvement (following the skills group) may even have been a 'delayed effect' of the skills group. We can, for example, suggest a process whereby an improvement in prosocial behaviour (being nicer and more understanding to others) and reduction in destructive expression of anger (if only temporary) may have contributed to improvements in other areas of the child's life - for example, emotional symptoms, hyperactivity and social competence. Thus, overall, an improved social environment might, in many children have improved their general sense of contentment and well-being.

There is inevitably an element of speculation here. However, the point is that the further improvements in key measures such as emotional symptoms, hyperactivity and positive coping, may as plausibly be attributed to a delayed effect of the group as to a routine process of maturation. Neither alternative, however, undermines the observation that the maintenance of improvements generated by the skills group in key areas indicated they were not merely transient. 
The findings, furthermore, provide some support for 'whole class' working, an underpinning philosophy of the approach. Rather than identify the 'troublemakers' and work with them as individuals or in groups, this approach focused on the whole class, including those who were not seen as presenting difficulties, as well as those who were. The potential benefits of this approach are clear - that no child is 'singled out' (and possibly stigmatised) for help; the work is undertaken on an environment that is, from the children's point of view, enduring, increasing the chances of maintaining any improvements; and the setting is a 'natural' one - it is an environment which is routinely experienced by the children. It is, in other words, working as much with the environment as the children themselves.

The study can be viewed more widely, however, than the possible capacity of social workers to engage in social skills training and resilience development, important though they are. These findings remind us of the potential of social work to practice in new contexts, and at an earlier stage of prevention than is increasingly becoming the case. It is furthermore, potentially highly cost effective. This was a brief, time limited intervention. It was also carried out in a large group context - that is the classroom. Hence these social workers were able to engage with large numbers of children, with an efficient use of time, and to do so with some effectiveness.

It also emphasises the possible therapeutic potential of social work. However, it goes further than this. These social workers did not go through a training course to learn these skills, but rather used a training pack from which they taught themselves how to conduct this skills group. This 'unsupervised capacity' to acquire skills is potentially important. It may or may not be the case that all social workers have the abilities to engage as effectively in such heuristic practices, but these findings certainly indicate that at least some may do so, and as a result, practice effectively.

\section{Concluding Comments}

Some caution should be applied to claiming too much from these findings, which arise from a novel exploratory study for social work, as noted above. It does raise significant questions for social work, however, and its potential future direction. Does any arbitrary limitation of social work engagement in therapeutic activities that may arise from a predominantly assessment-review-case management role places possibly perverse restrictions on social work? Second, where there is an increasing emphasis on the promotion of resilience and well-being, rather than just the prevention of harm (important though the latter may be), do these findings provide some evidence that social workers may be able to play a part? These reflect the work of only two social workers, but might we find these capabilities more widely distributed in the profession? Third, might this indicate that social workers, when given the opportunity, can engage effectively in practice in novel arenas operating at an earlier stage of prevention than child protection? Is this particularly the case where the rationale for doing so is clearly worked out, as in this case? The findings 
here present a base - intriguing possibilities, suggesting social work can have a constructive and effective role, but this may be explored further through replication studies. 


\section{REFERENCES}

Ainscow, M., and Franics,A. (2005). Working together for children. A small scale evaluation of the work of the Manchester behaviour and education support teams, commissioned by excellence in cities http://www.eicmanchester.gov.uk/bip//index.htmM

Axford, N. and Little, M. (2006) 'Refocusing children's services towards prevention: lessons from the literature', Children \& Society, 20 4, pp. 299-312.

Bennett, P. (2006) 'Helpful and unhelpful practices in meeting the needs of pupils with emotional and behavioural difficulties', British Journal of Special Education, 33, pp 188-95.

Broadhurst, K., Wastell, D., White, S. (2010) 'Performing initial assessment: identifying the latent conditions for error at the front-door of local authority children's services', British Journal of Social Work, 40, pp 352-70

Buhs, E.S. \& Ladd, G.W. (2001) 'Peer rejection as an antecedent of young children's school adjustment: An examination of mediating processes' Developmental Psychology, 37, pp 550-560.

Capaldi, D.M., Crosby, L. \& Stoolmiller, M. (1996) Predicting the timing of first sexual intercourse for at-risk adolescent males. Child Development, 67, 2, pp 344-359.

Cohen, J. (1988). Statistical Power Analysis for the Behavioral Sciences Hillsdale, NJ, Lawrence Earlbaum.

Cowan, D. (2004). Guidance for the operation of behaviour \& education support teams.

http://www.dfes.gov.uk/behaviourimprovement/appendix 3b/indiex.cfm .

Conway, A. and McDonough, S. (2006) 'Emotional resilience in early childhood: developmental antecedants and relations to problem behaviour', Annals of the New York Academy of Sciences, 1094, pp 272-77

Daniel, B.(2002) The School Years: Assessing and Promoting Resilience in Vulnerable Children 2, London, Jessica Kingsley

DfCFS (Department for Children Schools and Families) (2003) Good Practice Guidance for the Establishment of Behaviour and Education Support teams http://www.dcsf.gov.uk/best/set up/index.cfm 
DfCFS (Department for Children Schools and Families) (2008) Behaviour Education and Support Teams http://www.dcsf.gov.uk/best/about BEST/index.cfm

Eisenberg, N and Mussen, P. (1989) The Roots of Prosocial Behavior in Children. Cambridge, Cambridge University Press

Fergusson, S.R., Horwood, J. \& Lynskey, M.T. (1995) 'The prevalence and risk factors associated with abusive or hazardous alcohol consumption in 16-year-olds', Source Addiction 90, 7, pp 935-946

Furlong, M.J., Smith, D.C. and Bates, M.P. (2002) 'Further development of the multidimensional school anger inventory: construction validation, extension to female adolescents, and preliminary norms', Journal of Psychoeducational Assessment, 20, pp 46-65.

Gifford-Smith, M.E. \& Brownell, C.A. (2002) 'Childhood peer relationships: Social acceptance, friendships and peer networks', Journal of School Psychology, 41, pp 235-284.

Gilligan, R. (2004) 'Promoting resilience in child and family social work: Issues for social work practice, education and policy', Social Work Education, 23, pp 93-104.

Goodman R (1997) 'The Strengths and Difficulties Questionnaire: A Research Note'. Journal of Child Psychology and Psychiatry, 38, pp 581-586.

Goodman, R. (2001). 'Psychometric properties of the strengths and difficulties questionnaire'. Journal of the American Academy of Child \& Adolescent Psychiatry, 40, 1337-1345.

Goodman R, Meltzer H, Bailey V (1998) 'The Strengths and Difficulties

Questionnaire: A pilot study on the validity of the self-report version'. European Child and Adolescent Psychiatry, 7, 125-130

Halsey, K., Gulliver, C., Johnson, A., Martin, K., and Kinder, K. (2005) Evaluation of Behaviour and Education Support Teams. Website accessed :

http://www.dfes.gov.uk/research/data/uploadfiles/RR706.pdf.

Liddle, H. (2004) 'Family-based therapies for adolescent alcohol and drug use: research contributions and future research needs', Addiction, 99, 2, pp 76-92

Lambert, M and Barley, D. (2002) 'Research summary on therapeutic relationship and psychotherapy outcome', Psychotherapy: Theory, Research, Practice, Training, 38, pp 357-61 
Loeber, R. \& Dishion, T. (1987) 'Antisocial and Delinquent Youths: Method for Their Early Idenfication'. In Burchard, J.D. \& Burchard, S.N. (Eds), Prevention of Delinquent Behavior: Conference on the Primary Prevention and Psychopathology, Vermont. Beverley Hills, CA, Sage

McCrystal, P. Percy, A. and Higgins, K. (2007) 'School exclusion drug use and antisocial behaviour at 15/16 years: Implications for youth transitions', Vulnerable Children and Youth Studies, 2, pp 181 - 190

Munro, E. (2011) The Munro Review of Child Protection. Final Report: A Child Centred System, London, Department for Education

Needham, B., Crosnoe, R. Muller, C. (2004) 'Academic Failure in Secondary School: The Inter-Related Role of Health Problems and Educational Context', Social Problems 51, pp 569-586

Patterson, G.R., Reid, J.B. \& Dishion, T.J. (1992) A Social Learning Approach Vol 4: Antisocial Boys, Eugene, OR, Castilla

Postle, K. (2002) 'Working "between the idea and the reality" - ambiguities and tensions in care managers' work.' British Journal of Social Work, 32, pp 335-351

Rutter, M. (2006) 'Implications of resilience concepts for scientific understanding' Annals of the New York Academy of Science, 1094, pp 1-12

Sheppard, M. and Clibbens, J. (2012) 'An examination of the preventive process: a comparison of Behaviour and Education Support team Work with Children's Services', Child Abuse Review, http://onlinelibrary.wiley.com/doi/10.1002/car.2203/pdf

Spence, S (1996a) Social Skills Training: Enhancing Social Competence with Children and Adolescents, Windsor, NFER Nelson.

Spence, S. (1996b) Social Skills training: Research and Technical Supplement,Dundee, Harley and Cox

Stallard-Nash, J. (2005). BEST (behaviour and education support teams). http://www.sgfl.org.uk/best

Thompson, R. (2006) Promoting Resilience in Children and Adolescents through Social Emotional and Cognitive Skills, London, Routledge 
TTRB (Teacher Training Resource Bank) (2010) Behaviour Improvement Programmes, http://www.ttrb.ac.uk/ViewArticle2.aspx?Contentld=14236. Accessed 12-03-12

Walker, H.M., Colvin, G. \& Ramsey, E. (1995) Antisocial Behavior in School: Strategies and Best Practices, Pacific Grove, CA, Brooks Cole

Wilson, S.J. and Lipsey, M.W. (2007) 'School based interventions for aggressive and disruptive behaviour: update of a meta analysis', American Journal of Preventive Medicine, 33, 2, (Supplement 1), pp S30-143 
Table 1: 'Clinical' levels of problems in two classes (SDQ measures)

\begin{tabular}{|c|c|c|c|c|}
\hline & \multicolumn{2}{|c|}{ School A } & \multicolumn{2}{|c|}{ School B } \\
\hline & Number & $\%$ & Number & $\%$ \\
\hline Emotional & 4 & 19 & 2 & 10 \\
\hline Conduct & 3 & 14 & 4 & 19 \\
\hline Hyperactivity & 1 & 5 & 5 & 24 \\
\hline Peer problems & 9 & 43 & 1 & 5 \\
\hline Overall & 3 & 14 & 3 & 14 \\
\hline $\begin{array}{l}\text { Prosocial } \\
\text { behaviour }\end{array}$ & 1 & 5 & 3 & 14 \\
\hline Total & 21 & 100 & 21 & 100 \\
\hline
\end{tabular}

Note in both schools a further $10 \%$ were borderline, making a quarter actual or borderline 'clinical' status. 
Table 2: Emotional behavioural and social outcomes (SDQ measures)

\begin{tabular}{|c|c|c|c|c|c|}
\hline & Improvement* & No. & Mean Rank & $\begin{array}{l}\text { Sum of } \\
\text { Ranks }\end{array}$ & $\begin{array}{c}\text { Mean } \\
\text { change }\end{array}$ \\
\hline \multirow{3}{*}{$\begin{array}{l}\text { Emotional } \\
\text { symptoms }\end{array}$} & $E>C$ & 11 & 15.5 & 180.5 & $E=0.16$ \\
\hline & $C>E$ & 15 & 12.03 & 170.5 & $\mathrm{C}=0.02$ \\
\hline & Ties & 16 & & & \\
\hline \multirow{3}{*}{$\begin{array}{l}\text { Conduct } \\
\text { problems }\end{array}$} & $E>C$ & 11 & 8.8 & 96.5 & $E=-0.3$ \\
\hline & $C>E$ & 6 & 9.4 & 56.5 & $C=0.07$ \\
\hline & Ties & 25 & & & \\
\hline \multirow[t]{3}{*}{ Hyperactivity } & $E>C$ & 13 & 17.7 & 230.5 & $E=0.12$ \\
\hline & $\mathrm{C}>\mathrm{E}$ & 14 & 10.5 & 147.5 & $\mathrm{C}=0.50$ \\
\hline & Ties & 15 & & & \\
\hline \multirow[t]{3}{*}{ Peer problems } & $E>C$ & 15 & 17.0 & 255.5 & $E=-0.45$ \\
\hline & $\mathrm{C}>\mathrm{E}$ & 15 & 14.0 & 209.5 & $C=-0.31$ \\
\hline & Ties & 12 & & & \\
\hline \multirow{3}{*}{ Overall SDQ } & $E>C$ & 20 & 18.2 & 364.5 & $E=-0.5$ \\
\hline & $C>E$ & 15 & 17.7 & 265.5 & $C=0.28$ \\
\hline & Ties & 7 & & & \\
\hline \multirow{3}{*}{$\begin{array}{l}\text { Prosocial } \\
\text { Behaviour }\end{array}$} & $E>C$ & 21 & 17.2 & 360.5 & $E=0.33$ \\
\hline & $C>E$ & 9 & 11.6 & 104.5 & $C=-0.71$ \\
\hline & Ties & 12 & & & \\
\hline
\end{tabular}

*Scores based on follow up minus baseline. Improvement = follow up score lower than baseline. Deterioration = follow up score higher than baseline

${ }^{*}$ Prosocial behaviour score based on follow up minus baseline. Improvement $=$ follow up score higher than baseline. Deterioration = follow up score lower than baseline.

Test: Wilcoxon signed rank test

$\begin{array}{lcc} & \mathrm{Z} & \mathrm{p} \\ \text { Emotional symptoms } & -0.13 & \mathrm{n} / \mathrm{s} \\ \text { Conduct problems } & -0.53 & \mathrm{n} / \mathrm{s} \\ \text { Hyperactivity } & -1.01 & \mathrm{n} / \mathrm{s} \\ \text { Peer problems } & -.0 .48 & \mathrm{n} / \mathrm{s} \\ \text { Overall SDQ } & -0.81 & \mathrm{n} / \mathrm{s} \\ & & \\ \text { Prosocial behaviour } & -2.66 & 0.008\end{array}$


Table 3: Outcome - Social Competence and Anger Management

\begin{tabular}{|c|c|c|c|c|c|}
\hline & Improvement ${ }^{*}$ & No. & $\begin{array}{l}\text { Mean } \\
\text { Rank }\end{array}$ & $\begin{array}{l}\text { Sum of } \\
\text { Ranks }\end{array}$ & $\begin{array}{l}\text { Mean } \\
\text { change }\end{array}$ \\
\hline \multirow{3}{*}{$\begin{array}{l}\text { Social } \\
\text { competence }\end{array}$} & $E>C$ & 19 & 20.29 & 385.50 & $E=0.93$ \\
\hline & $C>E$ & 16 & 15.28 & 244.50 & $C=-0.60$ \\
\hline & Ties & 7 & & & \\
\hline \multicolumn{6}{|l|}{ Anger } \\
\hline \multirow{3}{*}{$\begin{array}{l}\text { Destructive } \\
\text { expression }\end{array}$} & $E>C$ & 23 & 21.48 & 494.00 & $E=-.0 .52$ \\
\hline & $\mathrm{C}>\mathrm{E}$ & 14 & 14.93 & 209.00 & $C=1.40$ \\
\hline & Ties & 5 & & & \\
\hline \multirow{3}{*}{$\begin{array}{l}\text { Positive } \\
\text { Coping }\end{array}$} & $E>C$ & 21 & 20.69 & 434.50 & $E=-0.31$ \\
\hline & $C>E$ & 18 & 19.19 & 345.50 & $C=-0.86$ \\
\hline & Ties & 3 & & & \\
\hline
\end{tabular}

Scores based on follow up minus base. Improvement in social competence and positive coping entailed a higher follow- up score compared with the base. Improvement in (lessening of) destructive expression entailed a lower follow-up score compared with the base.

Test: Wilcoxon signed rank test

$\begin{array}{lcl} & \mathrm{Z} & \mathrm{p} \\ \text { Social Competence } & -1.16 & \mathrm{n} / \mathrm{s} \\ \text { Destructive expression } & -2.15 & 0.031 \\ \text { Positive Coping } & -0.62 & \mathrm{n} / \mathrm{s}\end{array}$


Table 4: Outcome - Number of Friends

\begin{tabular}{lcccc}
\hline & No. & Mean & s.d. & $\begin{array}{c}\text { Std error } \\
\text { mean }\end{array}$ \\
\hline E Group & 42 & 1.71 & 3.90 & 0.60 \\
C Group & 42 & -0.57 & 3.22 & 0.50 \\
E Group - C & & 2.29 & 6.16 & 0.95 \\
Group change & & & & \\
\hline
\end{tabular}

Test: T-test

Significance: $\quad t=2.41 \quad d f=41 \quad p=0.021$ 
Table 5: Maintenance of emotional behavioural and social outcomes (SDQ)

\begin{tabular}{|c|c|c|c|c|c|}
\hline & Improvement ${ }^{*}$ & No. & $\begin{array}{l}\text { Mean } \\
\text { Rank }\end{array}$ & $\begin{array}{l}\text { Sum of } \\
\text { Ranks }\end{array}$ & $\begin{array}{c}\text { Mean } \\
\text { change }\end{array}$ \\
\hline \multirow{3}{*}{$\begin{array}{l}\text { Emotional } \\
\text { symptoms }\end{array}$} & Improvement & 13 & 7.31 & 95 & -1.0 \\
\hline & deterioration & 1 & 120 & 10 & \\
\hline & Ties & 7 & & & \\
\hline \multirow{3}{*}{$\begin{array}{l}\text { Conduct } \\
\text { problems }\end{array}$} & Improvement & 3 & 4.00 & 12 & -0.05 \\
\hline & Deterioration & 3 & 3.00 & 9 & \\
\hline & Ties & 15 & & & \\
\hline \multirow[t]{3}{*}{ Hyperactivity } & Improvement & 11 & 7.64 & 84.00 & -0.76 \\
\hline & Deterioration & 3 & 7.00 & 21.00 & \\
\hline & Ties & 7 & & & \\
\hline \multirow{3}{*}{$\begin{array}{l}\text { Peer } \\
\text { problems }\end{array}$} & Improvement & 9 & 6.72 & 60.50 & -0.48 \\
\hline & Deterioration & 3 & 5.83 & 17.50 & \\
\hline & Ties & 9 & & & \\
\hline \multirow[t]{3}{*}{ Overall SDQ } & Improvement & 16 & 12.63 & 202.0 & -2.29 \\
\hline & Deterioration & 5 & 5.80 & 29.0 & \\
\hline & Ties & 0 & & & \\
\hline \multirow{3}{*}{$\begin{array}{l}\text { Prosocial } \\
\text { Behaviour }\end{array}$} & Improvement & 7 & 6.29 & 44.0 & 0.19 \\
\hline & Deterioration & 4 & 5.50 & 22.0 & \\
\hline & Ties & 10 & & & \\
\hline
\end{tabular}

*For areas except for prosocial behaviour, a negative score indicates an improvement (i.e. lower scores at 3 months after follow up). For prosocial behaviour a positive score indicates an improvement (higher score at 3 months after follow up).

Test: Wilcoxon signed rank test

$\begin{array}{lcc} & \mathrm{Z} & \mathrm{p} \\ \text { Emotional symptoms } & -2.73 & 0.006 \\ \text { Conduct problems } & -0.33 & \mathrm{n} / \mathrm{s} \\ \text { Hyperactivity } & -2.02 & 0.043 \\ \text { Peer problems } & -1.73 & \mathrm{n} / \mathrm{s} \\ \text { Overall SDQ } & -3.02 & 0.003\end{array}$

Prosocial behaviour $\quad-1.07 \quad \mathrm{n} / \mathrm{s}$ 
Table 6: Maintenance - Social Competence and Anger Management

\begin{tabular}{llcccc}
\hline & Improvement & No. & $\begin{array}{c}\text { Mean } \\
\text { Rank }\end{array}$ & $\begin{array}{c}\text { Sum of } \\
\text { Ranks }\end{array}$ & $\begin{array}{c}\text { Mean } \\
\text { change }^{*}\end{array}$ \\
\hline $\begin{array}{l}\text { Social } \\
\text { competence }\end{array}$ & Improvement & 10 & 9.60 & 96.0 & 1.85 \\
& $\begin{array}{l}\text { Deterioration } \\
\text { Ties }\end{array}$ & 5 & 4.80 & 24.0 & \\
$\begin{array}{l}\text { Anger } \\
\text { Destructive }\end{array}$ & $\begin{array}{l}\text { Improvement } \\
\text { expression }\end{array}$ & 3 & 7.33 & 114.0 & 2.05 \\
& $\begin{array}{l}\text { Deterioration } \\
\text { Ties }\end{array}$ & 13 & 8.77 & 22.0 & \\
$\begin{array}{l}\text { Positive } \\
\text { Coping }\end{array}$ & $\begin{array}{l}\text { Improvement } \\
\text { Deterioration }\end{array}$ & 12 & 10.67 & 25.0 & 2.90 \\
& Ties & 5 & 5.00 & 128.0 & \\
& & 5 & & & \\
\hline
\end{tabular}

*Scores based on 3 months follow up (T3) minus follow up (T2). For social competence and positive coping a positive score indicates an improvement. For destructive expression a negative score indicates an improvement.

Test: Wilcoxon signed rank test

$\begin{array}{lcc} & \mathrm{Z} & \mathrm{p} \\ \text { Social Competence } & -2.05 & 0.04 \\ \text { Destructive expression } & -2.39 & 0.017 \\ \text { Positive Coping } & -2.44 & 0.015\end{array}$


Table 7: Maintenance: change in number of friends

\begin{tabular}{|c|c|c|c|c|}
\hline & No. & Mean & s.d. & $\begin{array}{c}\text { Std error } \\
\text { mean }\end{array}$ \\
\hline T3-T2 & 21 & 1.29 & 4.87 & 1.06 \\
\hline \multicolumn{5}{|l|}{ Test: T test } \\
\hline Significance: & $t=-1.2$ & $d f=20$ & & \\
\hline
\end{tabular}


Table 8: Medium and Large Effects Size where significant differences are found

\begin{tabular}{|c|c|c|c|c|c|c|c|}
\hline & & Cha & & & & & \\
\hline & Experin & àroup & Contr & roup & & ect Siz & \\
\hline & Mean & SD & Mean & SD & $\begin{array}{c}\text { Cohen's } \\
d\end{array}$ & $\mathrm{R}$ & $\mathrm{R}^{2}$ \\
\hline $\begin{array}{l}\text { Prosocial } \\
\text { behaviour }\end{array}$ & 0.33 & 1.42 & -0.71 & 1.44 & 0.73 & 0.34 & $\begin{array}{c}0.12 \\
(12 \%)\end{array}$ \\
\hline $\begin{array}{l}\text { Number of } \\
\text { Friends }\end{array}$ & 1.71 & 3.90 & -0.57 & 3.22 & 0.64 & 0.30 & $\begin{array}{l}0.09 \\
(9 \%)\end{array}$ \\
\hline $\begin{array}{l}\text { Destructive } \\
\text { Expression }\end{array}$ & -0.52 & 0.43 & 1.40 & 4.24 & 0.64 & 0.22 & $\begin{array}{l}0.09 \\
(9 \%)\end{array}$ \\
\hline & & Mair & hance & & & & \\
\hline & & Sc & & & & & \\
\hline & Exper & end & 3 mont & Eollow- & & & \\
\hline $\begin{array}{l}\text { Emotional } \\
\text { Symptoms }\end{array}$ & 1.52 & 1.57 & 0.52 & 1.03 & 0.76 & 0.35 & $\begin{array}{c}0.12 \\
(12 \%)\end{array}$ \\
\hline Overall SDQ & 7.43 & 4.55 & 5.14 & 4.36 & 0.51 & 0.25 & $\begin{array}{l}0.60 \\
(6 \%)\end{array}$ \\
\hline
\end{tabular}




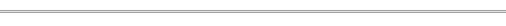

